Buor, D.

Gender and the utilisation of health services in the Ashanti Region, Ghana.

Health Policy: 69, 2004, nr. 3, p. 375-388

\begin{tabular}{|l|l|}
\hline Postprint Version & 1.0 \\
\hline Journal website & http://linkinghub.elsevier.com \\
Pubmed link & $\begin{array}{l}\text { http://www.ncbi.nlm.nih.gov/entrez/query.fcgi?cmd=Retrieve\&db=pubmed\&dop } \\
\text { t=Abstract\&list uids=15276316\&query hl=6\&itool=pubmed docsum }\end{array}$ \\
\hline DOI & $\underline{10.1016 / j . h e a l t h p o l .2004 .01 .004}$
\end{tabular}

\title{
Gender and the utilisation of health services in the Ashanti Region, Ghana
}

\author{
DANIEL BUOR *
}

Faculty of Social Sciences, Kwame Nkrumah University of Science and Technology, Kumasi, Ghana

\begin{abstract}
The survey seeks to structure a model for gender-based health services utilisation for the Ashanti Region of Ghana, and in addition, recommend intervention measures to ensure gender equity in the utilisation of health services. A sample size of 650 covered over 3108 houses, and the main research instruments were the questionnaire and formal interview. A multiple regression model is used for the analysis of the relationship between the complex independent variables and utilisation by gender. Results show that although females have a greater need for health services than males, they do not utilise health services as much. Secondly, whereas quality of service, health status, service cost and education have greater effect on male utilisation than females, distance and income have higher impact on female utilisation. It is recommended that, to ensure equity in health care utilisation, females be empowered through increased access to formal education and sustainable income opportunities. The introduction of a national health insurance scheme is also recommended to ensure adequate access by both sexes.
\end{abstract}

\section{INTRODUCTION AND BACKGROUND}

This paper addresses the role of gender in the utilisation of health services in the Ashanti Region of Ghana. Generally, utilisation of health services in developing countries is low. The low rate of utilisation is due to, among other factors, long distance to health facilities $[1,2]$, the unequal distribution of health facilities between the rural and urban areas [3], and poverty [4-7].

Demographic factors also play a meaningful role in the use of health services in developing countries. The demographic factor of sex shows some correla- tion with the use of health services. In the developing countries, where custom and tradition is predominant, especially in the rural areas such as the area under study, the discrimination by gender is likely to influence utilisation by women. In the study area, women are supposed to be subservient to men who dominate decision-making. Among some of those in which the agrarian occupation is predominant, the man takes custody of the income from farm proceeds. Even among women traders and those engaged in other income-generating activities, the man has access to the women's financial resources. The ability to purchase health resources is thus mostly dependent upon the man. Coupled with the generally low incomes in Ghana (the percentage of the population below the national poverty line being $31.4 \%$ for the rural population [8]), utilisation of health services by women especially, will be in serious jeopardy.

Another issue with women's inability to access health facilities is that they are saddled with domestic services such that, the time to attend a health facility to receive health care is limited, unless emergencies arise. They have to take care of the children and ensure that food, water, fuel wood and

\footnotetext{
*Tel.: +233-51-60182; fax: +233-51-60137. E-mail address: danielbuor@yahoo.com (D. Buor).
} 
other needs of the household are available. The time to spare to receive health care is thus a lot of precious time lost, except under cases of emergency.

There is also the issue of formal education, a strong determinant of utilisation of health services, in which the woman is discriminated against. In the study area, as in most other rural communities, the role of the woman, by culture, is basically domestic. Until in recent times when modernisation seems to be gradually penetrating the rural sector, to send a girl to school was considered a waste of time, energy and money. The woman is supposed to procreate and take care of the home. Most girls have therefore been denied schooling. The illiteracy factor has effects on utilisation. Education has been identified as a key predisposing factor in the Dutton's [9] model of utilisation. Other behavioural models identify it as such. To Jane and Heather female literacy is recognised as a further important variable influencing the use of health services and health outcomes [10]. In Ghana, about $40 \%$ of females above age 15 can neither read nor write. For males, the illiteracy rate is $22 \%$ [11]. With illiteracy come the problems of unemployment, poverty, low assessment of health need, taboos, selfmedication, little or no insurance and increasing use of traditional medicine.

It is thus clear that the man has several advantages over the women in the accessing of health facilities even though women's health needs are more than men, given their reproductive functions that serve as a drain on health. Good found that in India, women consulted traditional medical practitioners (TMPs) the most, and therefore, did not use scientific health services as much. They accounted for 55-60\% of consultations of TMPs [3]. In a study on women and health care in metropolitan Mumbai in Maharashtra, Nandraj et al. discovered that women had a higher morbidity rate than men across all the age groups. It was also revealed that there was underutilisation of health services by women both for deliveries and other illnesses [12].

A few works have however shown that women, especially in the reproductive age group, utilise health services more than men. In a study of the gender gap in primary health care resource in utilisation in Central Asia, Cashin et al. found that both in absolute and per capita terms, the principal users of primary health care are women of reproductive age and children under five. Women of reproductive age were found to consume approximately 1.5 times the average per capita primary health care resources, while men in the same age group consume approximately one-half of the average [13]. The study was however not related to the proportion of women in the reproductive age group needing the services, as compared to men. It could therefore not said to be scientific. This not withstanding, this trend cannot serve as a basis for concluding gender utilisation patterns since the use of secondary and tertiary services are urgent; especially for women who bear the burden of reproduction, with its attendant fatal health risks.

Gender disparities have a negative impact on the use of health services. Ojanuga and Gilbert, in a work on women's access to health care in developing countries, established the premise that a myriad of socio-cultural factors negatively impinge upon the physical well-being and accessibility of appropriate health care facilities of women [14]. Santow holds the position that in developing nations, women's roles affect their use of health services, since health, as a good is allocated, and the men who monopolise family decisions have a strong influence on who should utilise health care [15]. Given the physiology of women and the numerous problems that they encounter, especially with gynaecological complications, they must have abundant access to health services. Studies on morbidity and how it relates to utilisation show that adult women report more symptoms than men, who are more likely to use medical care $[16,17]$. In spite of such health problems by women in developing countries, their health needs have largely been neglected [18].

Other factors that influence the use of health services by women include education, income, insurance status and place of residence. In developing countries, the education of women influences their use of all types of modern health services [19]. In a study of the use of health services in the hill villages in central Nepal, Bhanu discovered that educated women used all forms of modern health services. In a study of accessibility, quality of care and prenatal care use in the Philippines, Wong et al. established that the education of women is associated with increased use of modern prenatal care [20]. In a study of factors related to the utilisation of prenatal care in Vietnam, Swenson et al. found that the woman's educational level and total number of living children were the most significant predictors of prenatal care utilisation [21]. To Jane and Heather female literacy is recognised as a further important variable influencing the use of health services and health outcomes [10]. In Ghana, however, about $40 \%$ of females above the age of 15 can neither read nor write. For males, the 
illiteracy rate is $22 \%$ [11]. When these percentages are converted into numbers, it would be realised that the differences are very large.

Poverty is a factor generally considered as a cause of poor utilisation of health services in developing countries. Habib and Vaughan, in a household survey in rural Iraq, found that the use of higher-level government health services and private clinics did increase substantially with increasing income [4]. In a survey of the influence of income, education, and work status on women's well-being, Mead et al. observed that women living in poverty are less likely than their higher-income counterparts to have health insurance and use preventive services, and more likely to have access problems, suffer from chronic illnesses, and report low overall health scores [22]. In Ghana, most women are homemakers, hence, earn little or no income. Their services are not quantified in monetary terms.

Health insurance is a strong determinant of hospital use in both developed and developing countries [23-26]. In a study of the Bwamanda hospital insurance scheme in Zaire (now Democratic Republic of the Congo), Criel et al. found that utilisation increased among insured patients [26]. Access to health insurance, without doubt, is a function of education, is very low for women, as compared to men.

The other factor of utilisation is the place of residence. Health facilities in developing countries tend to be concentrated in the urban centres; so revealed access by both men and women in the urban centres would tend to be higher. The Metro-Manila region in the Philippines, though contains $25 \%$ of the country's population, has $43 \%$ of total hospital beds [27]. In Kenya, it is estimated that only $10 \%$ of the country's doctors serve rural areas, and that some $70 \%$ of all doctors are in urban private practice. Doctor-to-population ratios range from 1:990 in the cities to 1:70,000 in the rural areas [2]. Since education of women influences their utilisation of health services and the urban areas are centres of educational institutions, utilisation would tend to be higher in the urban centres.

In Ghana, full access to health services is as low as $25 \%$ of the total population [28]. The World Bank is silent on differences by gender. With discrimination by culture and the relatively low level of education of women, a factor that determines health care use, effective access to health care by women is bound to be lower than their male counterparts. In Ghanaian societies, the authority structure weighs more in favour of the husband who monopolises decision-making [29], and such decisions include accessing health care. Within the elite (educated) nuclear family, the pattern of relationship between husband and wife tends to be one of shared roles, greater intimacy and equality [30].

Incomes are generally low in Ghana. The percentage of the population below the national poverty line is $31.4 \%$, and it is $34.3 \%$ for rural and $26.7 \%$ for urban [8]. Currently, the daily minimum wage is just above US\$ 1 . Women are more affected by the income problem, since most of them are homemakers so do not earn real incomes.

The concentration of health facilities is in the urban areas of Ghana that have high-income opportunities and educational facilities that are an advantage in access and use of health services. In Ghana, the two teaching hospitals are located in the two main metropolises of Ghana: Accra and Kumasi whilst all the remaining eight regional hospitals are in the regional capitals. The rural areas boast, at best, of rural health centres and a few private hospitals. In the Ashanti Region of Ghana (Fig. 1) that is selected for this study, about $50.6 \%$ of all hospitals are concentrated in the Kumasi metropolis [31], which constitutes less than $33 \%$ of the regional population [32] and about $1 \%$ of the regional land area [33].

\section{[ FIGURE 1 ]}

Given that females are a vulnerable group, by virtue of their reproductive role and complex health conditions, and given that they are responsible for the health care of their children in the Ghanaian culture and lifestyle, there is the need for a thorough investi gation into their utilisation patterns of health services, as compared with their counterparts to establish facts on equity in health care. The bottlenecks to their utilisation must be identified as a basis for structuring a policy framework for utilisation of health services by gender. This paper is basically to structure a model of utilisation of health services by gender using primary data from two districts in Ghana, urban and rural, and by this study, recommend effective intervention measures. 
Buor, D.

Gender and the utilisation of health services in the Ashanti Region, Ghana.

Health Policy: 69, 2004, nr. 3, p. 375-388

\section{OBJECTIVES AND HYPOTHESES}

The main objectives of this paper are to evolve a model of utilisation by gender and to recommend effective intervention measures. The specific objectives of this paper are to:

1. examine the male-female differences in the utilisation of health services in the Ashanti Region;

2. examine, in a multivariate framework, the significant factors that influence the utilisation of health services by gender;

3. structure a schematic model of utilisation of health services by gender;

4. recommend proactive intervention measures to remove the bottlenecks in the utilisation of health services by the female population.

The study was guided by three hypotheses. First, women are more likely to be influenced by income, distance, education and service cost in the utilisation of health services. Second, quality of service has a greater effect on males than females. Third, health status has a greater effect on males than females in the utilisation of health services.

\section{THEORETICAL BACKGROUND}

Whereas a general framework for utilisation of health services has been structured, very little has been done about the utilisation of health services by gender. Most works have centred on Andersen and Newman's behavioural, predisposing-enabling-need (PEN) model [34] which discussed gender and utilisation under the broad framework of predisposing factors. There have also been quantitative models like Morrill and Earickson [35,36]. Aday and Andersen's input-output model [37], and Dutton's model [9] which addressed physician-user-provider characteristics as well as structural barriers were all a modification of Andersen-Newman model. Some of the most recent works are by Oppong and Hodgson [38] and Andersen [39] and Carmen et al. [40].

Examining the spatial accessibility to health care in a rural district in Ghana, Oppong and Hodgson concentrated on physical accessibility factors primarily, whilst Andersen's new framework only introduces the controversial health outcomes as a factor in utilisation. There is thus a vacuum in the studies in utilisation of health services by gender, that of isolating certain variables for thorough investigation using a multivariate technique, and structuring an explanatory model for the genderutilisation syndrome. Albizu-Garcia et al. examine gender and health services for a mental health problem in Puerto Rico using Andersen's socio-behavioural model. He isolated mental health so did not give a broad coverage of utilisation of health services by gender. For a broader coverage of the problem, Andersen's behavioural model shall combine with physical factors like distance, travel time and waiting time, which constitute restrictive factors of utilisation. This study therefore examines four broad dimensions of utilisation namely, predisposing factors, need factors, enabling factors and restrictive factors.

\section{METHODS}

\subsection{Study design}

This study is a cross-sectional survey covering two districts, Ahafo-Ano South (rural) and Kumasi Metropolis (urban) (Fig. 1), of the eighteen administrative districts in the Ashanti Region of Ghana. The Ahafo-Ano South District and Kumasi Metropolis are respectively representative of rural and urban districts in the region and the country as a whole. The Ashanti Region from which the two districts were selected is the most cosmopolitan in the country, assembling all classes of people with diverse socio-cultural and economic characteristics. Data for the analyses were collected between August 2000 and February 2001. The predictor and independent variables were obtained during the same period when the raw data were collected. 


\subsection{Sampling and data collection}

The target population included socio-economic and cultural diversity, made up of individuals of 18 and above. The minimum age of maturity is pegged at 18. At this age, a person is considered as an adult and could exercise his/her franchise. This assumes that an adult shall have completed secondary school and may be entering a tertiary institution; so that this study regards such a person to be independent enough to take decisions on his health needs. A sample of 650 made up of 400 from the rural district (which, supposedly, has more accessibility and utilisation problems) and 250 from the urban district was used for the study. With regard to gender, the proportions were $60 \%$ for females, and who have greater barriers to access to health care but who need health services most. The proportion is a reflection of the lower sex ratio. The samples were thus 390 and 260 for females and males, respectively. The respondents were selected from sub-strata including age, income, marital status and educational status from both rural-urban strata. In all, seventeen settlements, 7 from the metropolis and 10 from the rural district were selected for the survey, and 3108 houses (1732 for the rural district and 1376 for the urban district) were involved in the sample survey in which the systematic procedure was used for selecting the sample. The selection took into consideration the distribution of health facilities and road network.

Data were collected from households using the questionnaire and formal interview instruments. The formal interview procedure was chosen because of the large illiterate and semi-literate population since there is the advantage of avoiding frequent call-backs. Both open- and close-ended questions constituted the questionnaire some of which were ranked for ease of coding and quantitative analysis. There were also a few non-responses, 10 in the metropolis and 16 in the rural district. These could constitute potential sources of bias. Such bias was limited because substitutes of similar characteristics were found. There were a few missing values in the administered questionnaire.

\subsection{The study variables}

The dependent variable for the study is utilisation of health services, which is operationalised as the number of times a person attended a hospital or health centre to receive health care the last three times he or she experienced illness spells. ${ }^{1}$ The independent variables are grouped into four categories namely pre- disposing, enabling, need and restrictive factors. The variables are age, education and employment as predisposing variables; income and health insurance as enabling variables; health status as need variable; and distance, travel time, waiting time, service cost, quality of service, transport cost, and attitude of medical staff as restrictive factors.

Age affects utilisation in the sense that different age groups have peculiar health conditions, and the health conditions for women in the reproductive age group differ from those who have attained menopause. Education has a great impact on utilisation, as revealed by several survey results, especially for women. Income and health insurance, the enabling factors, are very crucial in determining health care use in an economy where poverty is predominant. Distance is an important factor impeding utilisation in developing countries, and this could have an influence on a typical vulnerable group like women. Service cost is about the main factor influencing utilisation in developing countries, and is more likely to influence females who have a lower financial capability than males. A higher transport cost is more likely to affect females who have lower incomes than males. Travel and waiting times are likely to show differences in utilisation by gender due to the stress they generate, whilst the affective behaviour of medical staff could scare utilisation in an area where the need factor is not strong enough to influence utilisation. Women are more unlikely to bear the insults of medical staff than men. Health status, which identifies the need factor, is a key factor in utilisation. This is however subject primarily to the enabling factors.

\subsection{Statistical analysis}

Data were analysed quantitatively using both continuous and ranked data. Multiple regression was used in the analysis due to the nature of the data. Multiple regression is appropriate for the analysis

\footnotetext{
${ }^{1}$ In the study area, sickness is defined in terms of perceived illness. A person considers himself as sick if his condition is such that he cannot carry out his normal daily duties. Sickness is thus considered as such when severe. A patient thus seeks health care only when his condition is severe.
} 
since the variables are mostly continuous and ranked (ordinal). Variables of sex, employment and insurance which could not be ranked were entered as dichotomous variables. Values (ranked) were assigned to the non-continuous variables that influence utilisation. Utilisation was ranked from " 0 " for non-attendance of hospital for the last three times a respondent experienced sick spells, to " 3 " for attending for all three being respectively identified as rarely, irregularly, moderately and regularly. Health status was assessed by the number of sicknesses experienced within certain intervals. This ranged from " 1 " for falling sick once a week, to " 5 " for falling sick rarely. ${ }^{2}$ Another ranked variable that entered into the regression model was quality of health care, as assessed by respondents. The quantitative codes ranged from " 1 " for poor to " 4 " for very good. Respondents were guided by the following criteria: regular availability of a doctor; regularity of laboratory services; use of diagnostic facilities; time spent in consultation; availability and quality of drugs, and affective behaviour of medical and paramedical staff.

A multiple regression analysis was preceded by a bivariate correlation matrix to examine the strength of associations between the dependent and independent variables. This was also necessary to find out possible multicollinearity to exclude some variables that exhibit very strong correlation [41]. In the regression model, the variables that proved significant at a probability $(P)$ value equal to or less than 0.05 were selected. Values that were significant, using the stepwise method, were all put in a single regression model to get a common basis for comparison.

\section{RESULTS}

\subsection{Distribution of the study variables}

The distribution of the study variables is indicated in Table 1. Males utilise health services more than females who have a weaker health status. The difference is significant. Whereas females utilise health services more rarely, males utilise them more regularly. In the predisposing variables, the level of illiteracy is higher for females than for males, whilst there are far more males than females attaining higher education. The difference of the sexes by age is not significant. Regarding income, males have higher average incomes than females, and also a higher standard deviation for income than females, indicating wide disparities of income among males. Going by the grouped income data however, differences are not significant, whilst a greater percentage of males than females are insured.

\section{[ TABLE 1 ]}

Differences by distance, travel time, waiting time, quality of service, transport cost and staff attitude towards patients are not significant. For service cost, even though the difference is not significant, the average is higher for females than males. Females thus pay more for service cost than males. The standard deviation for females is higher than males.

\subsection{Multiple regression analysis}

Multiple regression analysis is used to examine the relative impacts of the independent variables on utilisation. Multiple regression analysis is preceded by a correlation matrix (Tables 2 and 3) to examine the association among the variables. Correlation coefficients are very strong between travel time and distance for both males and females. To avoid the problem of multicollinearity, travel time was eliminated from the multiple regression analysis. Theoretically, distance is a more significant factor in explaining utilisation behaviour than travel time. The variables that exhibit a relatively higher correlation with utilisation for males, following a descending order of significance, are distance, education, insurance, service cost and income; and for females, they are distance, travel time, education, income and service cost. Whereas the association between distance, income and travel time are stronger for females than males, that between insurance and service cost is stronger for males than females, whilst education is almost at par.

\footnotetext{
2 The assumption is that every health problem reported was severe.
} 
Buor, D.

Gender and the utilisation of health services in the Ashanti Region, Ghana.

Health Policy: 69, 2004, nr. 3, p. 375-388

\section{[ TABLE 2 ]}

\section{[ TABLE 3 ]}

The multiple regression (stepwise) results are indicated in Table 4. The stepwise method was used to select the key variables influencing utilisation; which were distance, education, service cost, income, quality of service and health status for males; and distance, income, education, service cost and transport cost for females, following a sequence of significance.

\section{[ TABLE 4 ]}

For the single regression model, based on common significant variables for both males and females, the variables that make significant impact on utilisation for males (in order of importance) are distance, education, service cost, quality of service, income and health status. For females, the variables are, distance, education, service cost and income. Whereas distance and income have greater effects on utilisation by females than males, education, service cost, health status, and quality of service, have greater effects on utilisation behaviour of males than females. Whereas the adjusted regression square (adjusted $R^{2}$ ) for males is 0.459 , it is 0.434 for females, implying that the results for males more adequately explain the utilisation situation more than females. Both are however averagely high, being based on a composite regression of above 0.6.

\section{DISCUSSION}

Males utilise health services more regularly than females, even though females have the greater need of health services, considering their comparatively weak health status. This has serious implications for gender equity in health care, especially taking cognisance of the fact that females are a vulnerable group in the Ghanaian society. They are also more influenced by income in the utilisation of health services than their male counterparts, and also pay higher for service cost than males. The average income for males is higher than for females. This puts women at a disadvantage in the utilisation of health services. This weak position of females in the utilisation of health services is reflected in the effect of distance decay on their utilisation behaviour. The selection of the sample was spatially balanced. Health facilities are scattered, apart from the core of the Kumasi metropolis, capital of the Ashanti Region. The effect of distance decay implies that females may not access specialist health services that are not equitably distributed in the region.

Males are more influenced by service cost but less by income. The difference in beta co-efficient is not too high. The predominant factor here is the ability to pay that is determined by income; and with females paying more for health care, the effect of the cost factor on them is considerable. Education affects males more than females. The education of females is generally low in the region, and for females, it is the most important predisposing factor, apart from distance, influencing utilisation. It is a more variable factor for males than for females, and this explains the difference in its effects on utilisation. Health status has a greater effect on males than females. Its effect on female utilisation behaviour is insignificant. The implication here is that more males than females who fall sick would decide to receive health care, even though females have a relatively weaker health status. This factor could be dependent on the predisposing factor of education and the enabling factor of income, and for the fact that females averagely pay more for service cost. Quality of service being an influential factor in the utilisation of health services for males than females could be explained by the income and education factors. Quality of service is compatible with high incomes. It is also a determinant of the level of education. It calls for a minimum level of education to appreciate what quality of care means and where to access it.

In general terms however, distance, education, service cost and income are the principal factor influencing utilisation in the region. The factors influencing utilisation tend to marginally favour males than females. Given the relatively weaker health status of females, and their vulnerability, it was expected that they would enjoy a higher utilisation rate. On the contrary, their male counterparts enjoy 
higher utilisation than they do. It calls for pragmatic policies to address the imbalance and ensure equity.

Some hypotheses have not been justified by the study. First, whereas females are more affected by distance and income than males in the use of health services, males are rather more influenced by education and service cost in their health care behaviour. The influence of education and service cost on women's health care use behaviour is however statistically significant. The hypotheses that quality of service and health status influence male more than females have however been justified.

A model of utilisation by gender (Fig. 2) emerges as a basis for hypotheses formulation and further surveys.

\section{[ FIGURE 2 ]}

The following facts underpin the emerging model:

1. Males utilise health services more than females.

2. Females have a relatively poorer health status, hence, their greater need for health services.

3. Income has a greater impact on female utilisation of health services.

4. Quality of service has a greater impact on male utilisation behaviour.

5. Education, distance and service cost have high effects on both males and females in the utilisation of health services.

The key components of the model are government policy, provider characteristics, male utilisation and female utilisation, with utilisation of health services at the centre. The survey has established that the rate of female utilisation is weaker, whilst government policy influences utilisation by both males and females. The distribution of the facilities, which is determined by government policy, would show how physically accessible both sexes are to them. Income affects females the more. Poverty appears to lie at the root of poor health service utilisation for both male and female, but greater for females. Government policy on wages and employment would financially empower the population, especially vulnerable females, to access health care, whilst universal education would positively influence utilisation for both males and females. Health insurance is a very effective strategy to improve utilisation, especially, by the vulnerable females. Such policies by government would affect utilisation for both male and female.

The provider of health services, the Ministry of Health through The Ghana Health Service, would also influence utilisation by both sexes. They ensure quality care, and their practice patterns would also ensure availability of services. Affective behaviour of medical staff would motivate utilisation. Government policy would influence provider characteristics since government is the main stakeholder of medical services in Ghana. Government policy and provider characteristics have been introduced to enhance the model. These have been extracted indirectly from the results and mainly from the literature review. The provider characteristics thus influence both males and females.

The survey brings to the fore certain pertinent issues that demand appropriate policies to ensure equity in the utilisation of health services. A policy to ensure easy access to health services is also urgent. There seems to be inequity in the utilisation of health services by gender, which defeats the moral basis of social welfare. Women have greater need for health services as indicated by their relatively poor health status. It is not mere accessing health care that matters, but quality health care to which males have greater access than females.

Females are a vulnerable group in society so they need much more attention, especially in a sensitive area such as health care. To adequately access quality health care requires a regular source of income and formal education. They must have access to income through gainful employment. Those without any form of formal education that could earn them employment should be introduced to some vocational training. The National Council on Women and Development (NCWD), a government institution to ensure the development and welfare of women, must be adequately resourced to carry out vocational training programmes, whilst government should encourage non-governmental organisations in the field of female vocational training. 
The survey has revealed that there is a gap between educational participation and attainment by gender. The education of the girl-child must be given priority. The government's Free Compulsory Universal Basic Education (FCUBE) policy must be carried to its logical conclusion, and females who have been at the periphery of educational attainment must be targeted in this crusade against mass illiteracy. There are several women who have passed the school-going age; however, education has been found to exhibit a positive relationship with the utilisation of health services. Efforts must be made by the Non-Formal Education Division (NFED) of the Ministry of Education to encourage them together with their male counterparts to participate in the informal education programme.

Finally, the status of insurance is rather low for both sexes. On the contrary, for quality health care and its easy access, there is the urgent need for a health insurance scheme. Currently, there is no national health insurance scheme for the country. There are some minimum health cost relief packages established by some public and private institutions for their workers. Such programmes are not sufficient enough to capitalise the health sector and to ensure adequate access. A National Health Insurance Scheme is urgent if health care would be brought to the doorsteps of the less privileged masses.

\section{CONCLUSION}

There is the need for equity in access to health care. This survey establishes that there is gender inequity in access to health care. Even though females show a weaker health status, and so have a greater need for health services, they relatively utilise health services less. Their poor access, related to the utilisation behaviour of their male counterparts, is caused mainly by abject poverty and long distances to health facilities.

Not only do females have a relatively poorer access to health services, but also they utilise poorer quality of service. Men have the advantage of utilising quality services. This could be due to their higher income status. A policy to remove gender inequity in the utilisation of health services would not only satisfy social justice, but will also ensure their safe health and positive contribution to socioeconomic development. Given that they constitute greater proportion of the population, their contribution to national development need not be overemphasised. A pragmatic wage and income policy, and female participation in family decisions are prerequisites. To participate in decisionmaking and to ensure their empowerment, they must be economically stable and have an appreciable level of formal education. Although males are affected by the service cost factor, given the higher average income for males than females, and the fact that females are more affected by income than males as reflected by the multiple regression results; and also the fact that they averagely pay higher service cost than males, the argument for their disadvantage in the utilisation could be advanced.

The survey has structured a model of utilisation by gender. It has succeeded in unearthing the intrinsic differences in the utilisation of health services by gender, using the existing general utilisation models as the basis. The multiple regression technique has also been used to show the relative contribution of various independent variables to the utilisation model. It must be emphasised that the survey has more than shown correlations rather than determining causes.

Further research areas have been exposed by the survey. First, to what extent does quality of service influence male utilisation? Second, the need of females for health care is statistically greater than for males, but the effect of health status on utilisation for females is not statistically significant. There is the need for a further survey on the effect of health status and utilisation on females, using a larger sample size. Third, the education factor influencing female use of health services needs to be examined in its broad dimensions.

\section{ACKNOWLEDGEMENTS}

This project is funded substantially by The Netherlands Foundation for the Advancement of Tropical Research (WOTRO), with logistic support from The Netherlands Institute for Health Services Research (NIVEL). I am grateful to Professors Jouke Van Der Zee and Peter Groenewegen, both of NIVEL, for their fruitful comments and contributions. 
Buor, D.

Gender and the utilisation of health services in the Ashanti Region, Ghana.

Health Policy: 69, 2004, nr. 3, p. 375-388

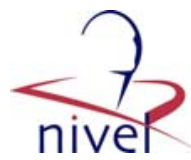

\section{TABLES AND FIGURES}

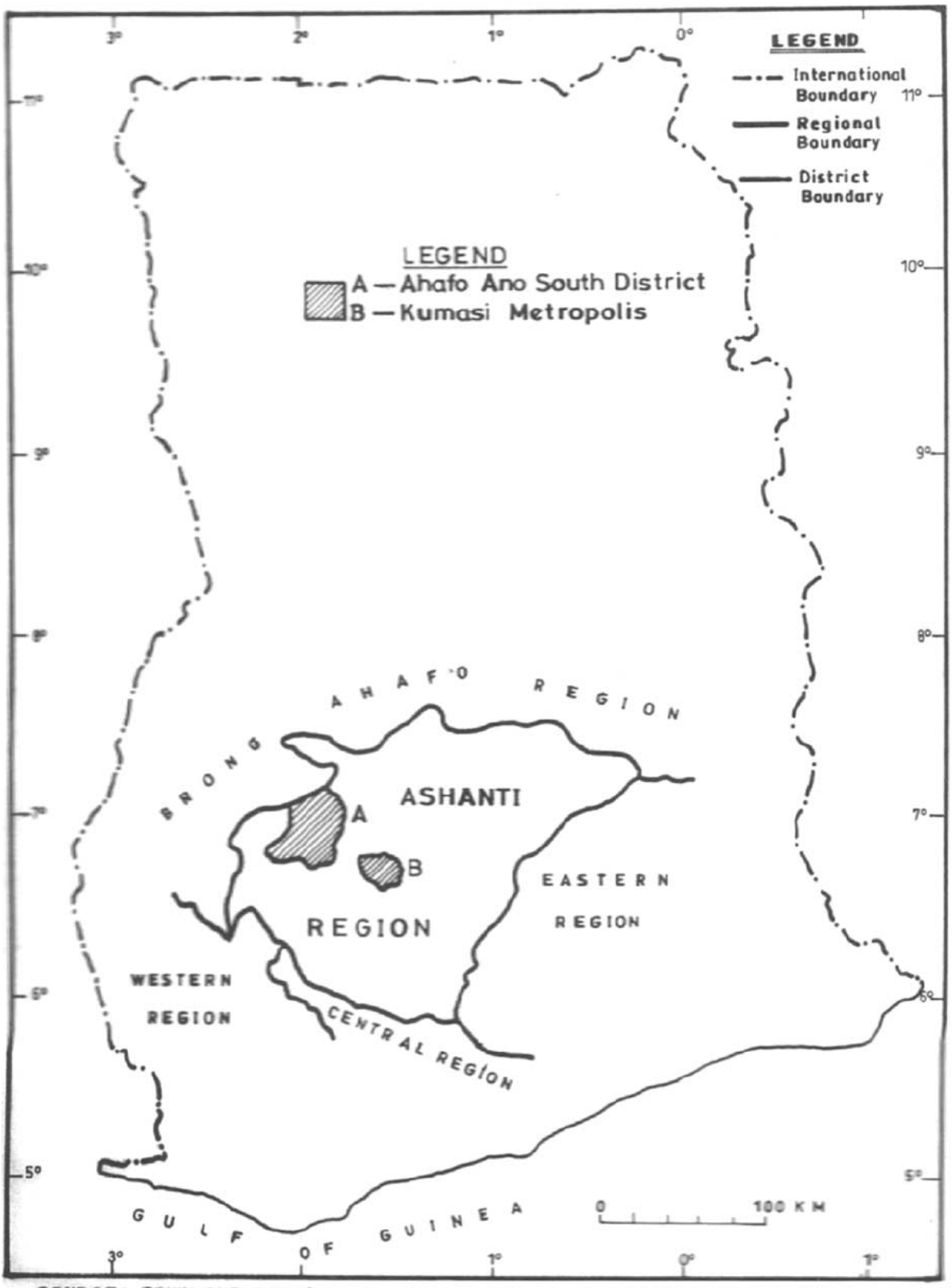

SOURCE: TOWN AND COUNTRY PLANNING DEPT KUMAST 1996

Fig. 1. Kumasi Metropolis and Ahafo Ano South district in Ashanti Region. 
Buor, D.

Gender and the utilisation of health services in the Ashanti Region, Ghana.

Health Policy: 69, 2004, nr. 3, p. 375-388

Table 1

Distribution of study variables by gender

\begin{tabular}{|c|c|c|c|c|c|c|c|}
\hline \multicolumn{4}{|c|}{ Distnoumon or study vanaores by gender } & \multirow{2}{*}{ Variable/sub-variable (\%) } & \multirow{2}{*}{$\begin{array}{l}\text { Male } \\
(n=260)\end{array}$} & \multirow{2}{*}{$\begin{array}{l}\text { Female } \\
(n=390)\end{array}$} & \multirow{2}{*}{$\begin{array}{l}\text { Significance } \\
\text { ( } P \text {-value })\end{array}$} \\
\hline \multirow[t]{2}{*}{ Variable/sub-variable (\%) } & \multirow{2}{*}{$\begin{array}{l}\text { Male } \\
(n=260)\end{array}$} & \multirow{2}{*}{$\begin{array}{l}\text { Female } \\
(n=390)\end{array}$} & \multirow{2}{*}{$\begin{array}{l}\text { Significance } \\
(P \text {-value })\end{array}$} & & & & \\
\hline & & & & S.D. & 26.6 & 26.1 & \\
\hline \multicolumn{4}{|l|}{ Predisposing } & \multicolumn{3}{|l|}{ Waiting time (min) } & \multirow{9}{*}{0.548} \\
\hline \multicolumn{4}{|l|}{ Education } & Less than 60 & 35.8 & 34.6 & \\
\hline Never-been-to school & 30.8 & 42.1 & & $61-120$ & 43.8 & 39.3 & \\
\hline Basic education & 28.8 & 32.1 & \multirow{3}{*}{0.000} & $121-180$ & 13.8 & 17.6 & \\
\hline Secondary education & 30.8 & 22.6 & & $181-240$ & 4.6 & 5.7 & \\
\hline Tertiary education & 9.6 & 3.3 & & $241+$ & 1.9 & 2.8 & \\
\hline \multicolumn{4}{|l|}{ Age } & Waiting time & {$[-]$} & [3] & \\
\hline $0-59$ & 78.1 & 81.3 & & Mean & 91.1 & 96.8 & \\
\hline $60+$ & 21.9 & 18.7 & 0.184 & S.D. & 71.4 & 78.3 & \\
\hline \multicolumn{4}{|l|}{ Employment } & \multicolumn{3}{|l|}{ Service cost $(\phi)$} & \multirow[b]{5}{*}{0.252} \\
\hline Employed & 93.7 & 89.0 & 0.028 & Less than 30000 & 45.0 & 39.5 & \\
\hline Unemployed & 6.3 & 11.0 & & $30000-50000$ & 27.9 & 32.3 & \\
\hline \multirow{2}{*}{ Missing } & \multirow{2}{*}[5]{} & \multirow{2}{*}[8]{} & & $51000-100000$ & 27.1 & 27.4 & \\
\hline & & & & Above 100000 & 0.0 & 0.8 & \\
\hline Enabling & & & & Missing & {$[2]$} & {$[-]$} & \\
\hline Income per month $(\phi)$ & & & & Mean & 35839 & 39067 & \\
\hline Less than 100000 & 21.2 & 21.4 & & S.D. & 25272 & 28617 & \\
\hline $100000-199000$ & 47.1 & 49.4 & & & & & \\
\hline $200000-299000$ & 17.4 & 13.4 & 0.254 & Quality of service & & & \\
\hline $300000-499000$ & 8.5 & 12.1 & & Poor & 1.9 & 1.6 & \\
\hline $500000+$ & 5.8 & 3.6 & & Satisfactory & 39.6 & 34.8 & 0.614 \\
\hline Missing & {$[1]$} & [3] & & Good & 45.4 & 49.9 & \\
\hline Mean & {$[382600]$} & [337263] & & Very good & 13.1 & 13.8 & \\
\hline S.D. & {$[548720]$} & {$[357692]$} & & Missing & {$[-]$} & {$[5]$} & \\
\hline Insurance & & & & Transport cost $(\phi)$ & & & \\
\hline Insured & 15.0 & 10.5 & 0.057 & Less than 500 & 31.5 & 31.5 & \\
\hline Uninsured & 85.0 & 89.5 & & $500-1000$ & 11.9 & 10.0 & 0.818 \\
\hline & & & & $1001-2000$ & 23.5 & 23.8 & \\
\hline Need & & & & $2001-4000$ & 13.5 & 11.3 & \\
\hline Health status (how many & times do y & u fall sick?) & & $4001-8000$ & 12.7 & 15.6 & \\
\hline Once a week & 0.8 & 2.1 & & $8001+$ & 6.9 & 7.7 & \\
\hline Once a fortnight & 7.3 & 5.9 & & Mean & 2609.6 & 2816.9 & \\
\hline Once a month & 22.7 & 29.7 & 0.000 & S.D. & 3767.2 & 4188.3 & \\
\hline Once in 3 months & 21.2 & 34.6 & & & & & \\
\hline Rarely & 48.1 & 27.7 & & Attitude of hospital staff & & & \\
\hline & & & & Poor & 3.1 & 5.4 & 0.511 \\
\hline Restrictive & & & & Satisfactory & 24.6 & 22.2 & \\
\hline Distance $(\mathrm{km})$ & & & & Good & 55.0 & 54.9 & \\
\hline Less than 3 & 35.7 & 34.5 & & Very good & 17.3 & 17.5 & \\
\hline $3-5$ & 17.4 & 18.4 & & Missing & {$[-]$} & {$[2]$} & \\
\hline $6-10$ & 11.2 & 13.2 & & & & & \\
\hline $11-15$ & 7.0 & 4.2 & 0.556 & Utilisation & & & \\
\hline $16+$ & 28.7 & 29.6 & & Rarely & 21.9 & 23.8 & 0.007 \\
\hline Missing & {$[2]$} & {$[5]$} & & Irregularly & 41.9 & 36.2 & \\
\hline Mean & [13.3] & [14.0] & & Moderately & 7.3 & 15.9 & \\
\hline S.D. & {$[16.7]$} & {$[17.6]$} & & Regularly & 28.8 & 24.1 & \\
\hline
\end{tabular}

Travel time $(\mathrm{min})$

$\begin{array}{llll}\text { Up to } 30 & 78.7 & 73.9 & \\ 31-60 & 13.0 & 14.2 & \\ 61+ & 10.3 & 11.8 & \\ \text { Missing } & {[7]} & {[18]} & 0.728 \\ \text { Mean } & 25.8 & 26.3 & \end{array}$

$N=650 ;$ S.D.: standard deviation. Source: Based on Field Data, 2001. 
Buor, D.

Gender and the utilisation of health services in the Ashanti Region, Ghana.

Health Policy: 69, 2004, nr. 3, p. 375-388

Table 2

Correlation matrix for the study variables for males and females

\begin{tabular}{|c|c|c|c|c|c|c|c|c|}
\hline \multirow[t]{2}{*}{ Variables } & \multicolumn{8}{|c|}{ Variables/correlations } \\
\hline & Age & Education & Employment & Income & Insurance & Health status & Travel time & Distance \\
\hline Age & 1.000 & $-0.387^{* *}$ & -0.002 & -0.088 & -0.035 & $-0.286^{* *}$ & $0.107^{*}$ & 0.079 \\
\hline Education & $-0.296^{* *}$ & 1.000 & 0.008 & $0.533^{* *}$ & $0.337^{* *}$ & $0.165^{* *}$ & $-0.153^{* *}$ & $-0.191^{* *}$ \\
\hline Employment & -0.062 & $0.131^{*}$ & 1.000 & -0.019 & -0.094 & 0.098 & 0.039 & 0.082 \\
\hline Income & 0.055 & $0.320^{* *}$ & 0.046 & 1.000 & $0.426^{* *}$ & 0.017 & $-0.205^{* *}$ & $-0.238^{* *}$ \\
\hline Insurance & 0.112 & $0.335^{* *}$ & -0.073 & $0.348^{* *}$ & 1.000 & 0.019 & $-0.191^{* *}$ & $-0.188^{* *}$ \\
\hline Health status & $-0.269^{* *}$ & $0.170^{* *}$ & 0.066 & -0.018 & 0.080 & 1.000 & -0.096 & -0.085 \\
\hline Travel time & 0.071 & -0.095 & 0.085 & $-0.143^{*}$ & -0.107 & -0.048 & 1.000 & $0.884^{* *}$ \\
\hline Distance & 0.079 & $-0.155^{*}$ & 0.118 & $-0.205^{* *}$ & $-0.208^{* *}$ & -0.104 & $0.778^{* *}$ & 1.000 \\
\hline Service cost & -0.067 & $-0.264^{* *}$ & 0.026 & $-0.212^{* *}$ & $-0.488^{* *}$ & 0.024 & 0.093 & $0.168^{* *}$ \\
\hline Waiting time & 0.092 & -0.116 & -0.074 & -0.100 & -0.007 & 0.046 & -0.005 & -0.037 \\
\hline Staff attitude & 0.088 & 0.069 & -0.004 & $0.141^{*}$ & 0.063 & $-0.160^{* *}$ & 0.093 & 0.091 \\
\hline Service quality & 0.094 & -0.048 & -0.086 & $0.155^{*}$ & 0.043 & $-0.148^{*}$ & 0.035 & 0.016 \\
\hline Transport cost & 0.115 & -0.066 & $0.127^{*}$ & 0.024 & -0.027 & $-0.145^{*}$ & $0.457^{* *}$ & $0.566^{* *}$ \\
\hline Utilisation & -0.026 & $0.421^{* *}$ & -0.014 & $0.371^{* *}$ & $0.395^{* *}$ & -0.065 & $-0.363^{* *}$ & $-0.484^{* *}$ \\
\hline
\end{tabular}

Values below the 1.000 diagonal are for males, and those above, for females. Source: Based on Field Data, 2001

* Correlation is significant at the 0.05 level (two-tailed).

** Correlation is significant at the 0.01 level (two-tailed).

Table 3

Correlation matrix for the study variables for males and females (continuation of Table 2)

\begin{tabular}{|c|c|c|c|c|c|c|}
\hline \multirow[t]{2}{*}{ Variables } & \multicolumn{6}{|c|}{ Variables/correlations } \\
\hline & Service cost & Waiting time & Staff attitude & Service quality & Transport cost & Utilisation \\
\hline Age & $0.118^{*}$ & 0.056 & 0.024 & 0.020 & -0.032 & $-0.128^{*}$ \\
\hline Education & $-0.112^{*}$ & 0.083 & -0.021 & 0.037 & 0.027 & $0.418^{* *}$ \\
\hline Employment & -0.066 & 0.009 & 0.021 & -0.016 & -0.069 & -0.013 \\
\hline Income & $-0.183^{* *}$ & 0.076 & -0.017 & 0.050 & -0.035 & $0.411^{* *}$ \\
\hline Insurance & $-0 ., 360^{* *}$ & 0.008 & 0.068 & -0.007 & -0.065 & $0.294^{* *}$ \\
\hline Health status & -0.039 & -0.040 & -0.047 & -0.077 & -0.069 & 0.015 \\
\hline Travel time & $0.208^{* *}$ & $0.209^{* *}$ & 0.025 & -0.004 & $0.342^{* *}$ & $-0.445^{* *}$ \\
\hline Distance & $0.198^{* *}$ & $0.118^{*}$ & 0.099 & 0.000 & $0.476^{* *}$ & $-0.503^{* *}$ \\
\hline Service cost & 1.000 & 0.052 & -0.062 & -0.005 & $0.159^{* *}$ & $-0.309^{* *}$ \\
\hline Waiting time & $0.156^{*}$ & 1.000 & $-0.387^{* *}$ & $-0.131^{*}$ & 0.034 & -0.027 \\
\hline Staff attitude & $-0.171^{* *}$ & $-0.393^{* *}$ & 1.000 & $0.571^{* *}$ & $0.110^{*}$ & -0.045 \\
\hline Service quality & -0.015 & $-0.23 \% \%^{* *}$ & $0.604^{* *}$ & 1.000 & $0.157^{* *}$ & $0.106^{*}$ \\
\hline Transport cost & $0.165^{* *}$ & 0.013 & 0.098 & $0.151^{*}$ & 1.000 & -0.072 \\
\hline Utilisation & $-0.392^{* *}$ & 0.005 & 0.090 & $0.134^{*}$ & $-0.188^{* *}$ & 1.000 \\
\hline
\end{tabular}

Values below the 1.000 diagonal are for males, and those above, for females. Source: Based on Field Data, 2001.

* Correlation is significant at the 0.05 level (two-tailed).

** Correlation is significant at the 0.01 level (two-tailed).

Table 4

Multiple regression factors

\begin{tabular}{|c|c|c|c|c|}
\hline \multirow[t]{2}{*}{ Variable } & \multicolumn{2}{|l|}{ Males } & \multicolumn{2}{|l|}{ Females } \\
\hline & $\beta$-coefficient & $P$-value & $\beta$-coefficient & $P$-value \\
\hline Distance & -0.424 & 0.000 & -0.452 & 0.000 \\
\hline Education & 0.295 & 0.000 & 0.213 & 0.000 \\
\hline Service cost & -0.235 & 0.000 & -0.187 & 0.000 \\
\hline Income & 0.126 & 0.015 & 0.186 & 0.000 \\
\hline Health status & -0.124 & 0.010 & -0.062 & 0.124 \\
\hline Quality of service & 0.129 & 0.010 & 0.064 & 0.113 \\
\hline Transport cost & 0.071 & 0.223 & 0.129 & 0.005 \\
\hline Waiting time & 0.108 & 0.028 & 0.002 & 0.959 \\
\hline Adjusted $R^{2}$ & \multicolumn{2}{|c|}{0.459} & \multicolumn{2}{|c|}{0.434} \\
\hline
\end{tabular}

Source: Based on Field Data, 2001. 
Buor, D.

Gender and the utilisation of health services in the Ashanti Region, Ghana.

Health Policy: 69, 2004, nr. 3, p. 375-388

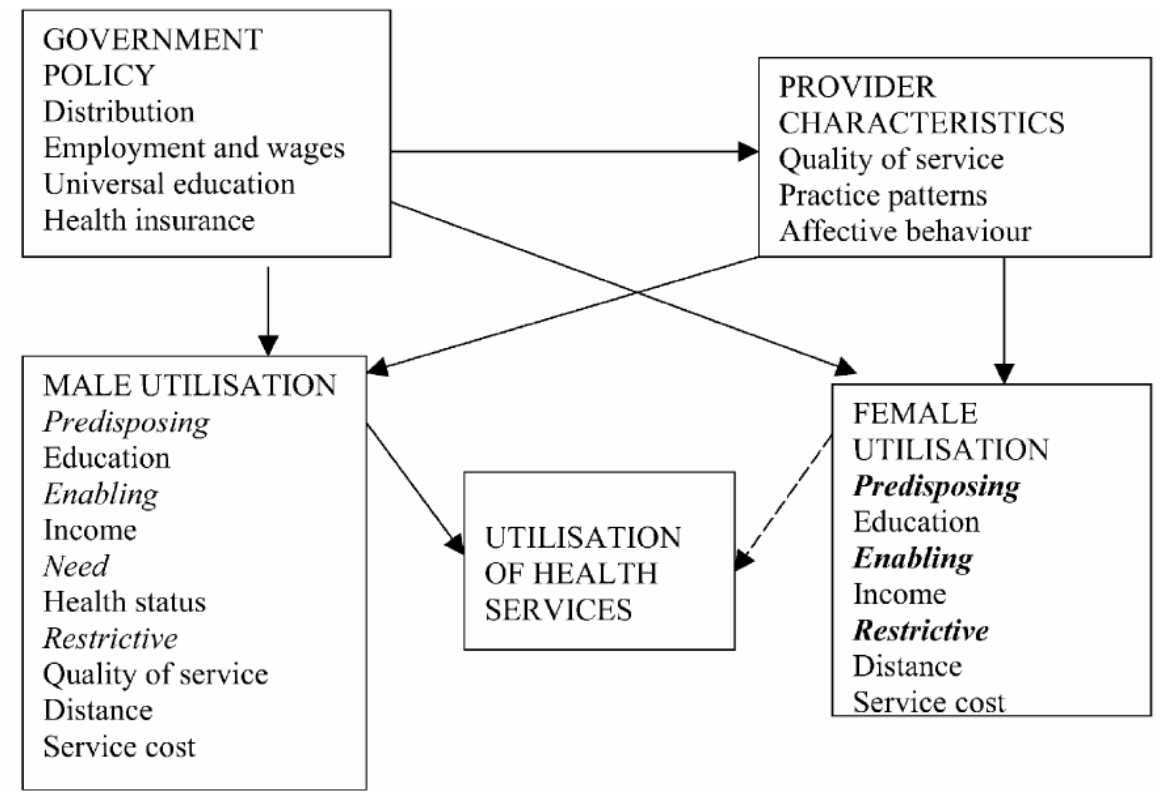

South: Author's Construct based on Survey Results, 2001

Fig. 2. A schematic diagram showing utilisation by gender in the Ashanti Region of Ghana.

\section{REFERENCES}

[1] Philips DR. The demand for the utilisation of health services. In: Pacione M, editor. Medical geography: progress and prospects. London: Groom Helm; 1996. p. 200-47.

[2] Stock R. Understanding health care behaviour: a model together with evidence from Nigeria. In:

Akhar R, editor. Health and disease in tropical Africa. London: Harwood; 1987. p. 279-92.

[3] Good CM. Ethnomedical systems in Africa: patterns of traditional medicine in rural and urban Kenya. New York: Guilford Press; 1987. p. 89-90.

[4] Habib OS, Guilkey DK, Griffin CC, Popkin BMK. The demand for primary health services utilisation in southern Iraq: a household interview survey. International Journal of Epidemiology 1986;15(3):359-403.

[5] Chernichovsky D, Meesook OA. Utilisation of health services in Indonesia. Social Science and Medicine 1986;23(6):611- 20.

[6] Ensor T, Pham-Bich-San. Access and payment for health care: the poor of Northern Vietnam. International Journal of Health Planning and Management 1996;11(1):69-83.

[7] Pickett G, Hanlon JJ. Public health administration and practice. St. Louis: Times Mirror/Mosby College Publishing; 1990. p. 541-2.

[8] The World Bank. World development indicators; 2000. p. 62.

[9] Dutton D. Financial organisational and professional factors affecting health care utilisation. Social Science and Medicine 1986;23(7):725-35.

[10] Jane R, Heather W. Invisible nursing: exploring health outcomes at a global level. Relationships between infant and under-5 mortality rates and the distribution of health professionals, GNP per capita, and female literacy. Journal of Advanced Nursing 2000;32(1):28-40.

[11] The World Bank. World development indicators; 2000. p. 82.

[12] Nadraj S, Madhiwalla N, Sinha R, et al. Women and health care in Mumbai (India): a study of morbidity, utilisation and expenditure on health care in the households of the metropolis. Centre for Enquiry into Health and Allied Themes; 1998.

[13] Cashin EC, Borowitz M, Zuess O. The gender gap in primary health care resource utilisation in Central Asia. Health Policy and Planning 2002;17(3):264-72.

[14] Ojanuja DN, Gilbert C. Women's access to health care in developing countries. Social Science and Medicine 1992;35(4):613-7.

[15] Santow G. Social roles and physical health: the case of female disadvantaged in poor countries. Social Science and Medicine 1995;40(2):147-61.

[16] Briscoe M. Why do people go to the doctor? Sex differences in the correlates of GP consultation. Social Science and Medicine 1987;25:507-13. 
Buor, D.

Gender and the utilisation of health services in the Ashanti Region, Ghana.

Health Policy: 69, 2004, nr. 3, p. 375-388

[17] Gijsbers Van Wijk CMT, Kolk AMM, Vanden Bosch WJHM, Vanden Hoogen HJM. Male and female morbidity in general practice: the nature of sex differences. Social Science and Medicine 1992;35:665-78.

[18] Lane SD, Meleis AI. Roles, work, health perceptions and health resources of women: a study in an Egyptian delta hamlet. Social Science and Medicine 1991;33(10):1197-208.

[19] Bhanu BN. Use of health services in hill villages in Central Nepal. Health Transition Review 1994;4:1151-66.

[20] Wong EL, Popkin BM, Guilkey DK, Akin JS. Accessibility, quality of care and prenatal care use in the Philippines. Social Science and Medicine 1994;24(11):927-44.

[21] Swenson IE, Thang NM, Nhan VQ, Tieu PX. Factors related to the utilisation of pre-natal care in Vietnam. Journal of Tropical Medicine and Hygiene 1993;96(2):76-85.

[22] Mead H, Witkowski K, Gault B, Hartmann H. The influence of income, education, and work status on women's well-being. Women's Health Issues 2001;11(3):160-72.

[23] Tilford JM, Robbins JM, Shema SJ, Farmer FL. Response to health insurance by previously uninsured rural children. Health Services Research 1999;34(3):765-75.

[24] Khandker RK, McCormack LA. Medicare spending by beneficiaries with various types of supplemental insurance. Medical Care Research and Review 1999;56(2):137-55.

[25] Fong $C$. The influence of health insurance status on nonurgent pediatric visits to the emergency department. Academic Emergency Medicine 1999;6(7):744-8.

[26] Criel B, Van-der-Stuyft P, Van-Lerberghe W. The Bwamanda hospital insurance scheme: effective for whom? A study of its impact on hospital utilisation patterns. Social Science and Medicine 1999;48(7):897-911.

[27] Philips DR. Primary health care in the Philippines: banking on the Barangays? Social Science and Medicine 1986;23(10):1105-17.

[28] The World Bank. World development indicators; 1997. p. 78.

[29] Nukunya GK. Tradition and change in Ghana. Accra: Ghana Universities Press; 1992. p. 208.

[30] Lloyd BB. Education and family life in the development of class identification among the Yoruba. In: Lloyd PC, editor. New elites in tropical Africa. London; 1966. p. 30.

[31] Ghana Ministry of Health, Ashanti Region. 1999 Annual health report. Kumasi, Ghana; 2000. p. 4.

[32] Ghana Statistical Service. 2000 Population and housing census, summary report of final results. Accra; 2002.

[33] Ghana Ministry of Health, Ashanti Region. 1999 Annual health report. Kumasi, Ghana; 2000. p. 3.

[34] Andersen R, Newman JF. Societal and individual determinants of medical care utilisation in the United States. Milbank Memorial Fund Quarterly 1973;81(Winter):95-123.

[35] Morrill RL, Earickson RJ. Hospital variation and patient travel distances. Inquiry 1968;5:1-9.

[36] Kon-Kyun R. Patient characteristics. Hospital characteristics, and hospital use. In: Fuchs VR, editor. Essays in the economics of health and medical care. New York: National Bureau of Economic Research; 1972. p. 70-2.

[37] Aday LA, Andersen R. A framework for the study of access to medical care. Health Services Research 1974;9:208-20.

[38] Oppong JR, Hodgson MJ. Spatial accessibility to health care in Suhum District, Ghana. The Professional Geographer 1994;46(2):121-37.

[39] Andersen RM. Revisiting the behavioral model and access to medical care: does it matter? Journal of Health and Social Behaviour 1995;36:1-10.

[40] Albizu-Garcia CE, Margarita A, Daniel F, Mildred V. Gender and health services use for a mental health problem. Social Science and Medicine 2001;53(7):865-78.

[41] Anderson DR, Sweeney DJ, Williams TA. Introduction to statistics: concepts and applications. 3rd ed. West: New York; 1994. p. 602-3. 